\section{BASEM moving from strength to strength: More education, more member benefits}

\author{
Eleanor J Tillett
}

Welcome to BASEM's highlight issue for 2014. Our mini theme edition focuses on rowing, as well as highlighting updates in clinical decision-making across the spectrum of sport and exercise medicine.

BASEM continues to build on its new foundation and we are now on a solid financial footing. Thanks to this we have been able to increase our sponsorship of educational and research opportunities and invest in the expansion of our learning programmes. Have a look at our website to review the range of travelling fellowships and research bursaries available (http://www.basem.co.uk/benefits-ofmembership.shtml). With our new website imminent, this will also allow us to delve into the field of online education, which will be available at discounted rates to BASEM members. As you will see from Babette Pluim's editorial (see page 1522), $B J S M$ is already demonstrating the value of learning in this way.

The previously popular 'Foundation' and 'Clinical Skills' courses have been revived and there are plans to run them again in June and January 2015, respectively. The FSEM Diploma Revision course continues to run annually with the next part 1 course in December 2014 and the next part 2 course in March 2015. Again, see our website for details of these and other courses.

Earlier this year, BASEM ran its first 'Exercise Medicine' course, which was very well received. Included in the

Correspondence to Dr Eleanor J Tillett, British Association of Sport and Exercise Medicine (BASEM), Suite 1C, Hutton Business Centre, Bentley Road, Doncaster DN5 9QP, UK; ejtillett@doctors.org.uk programme was a session (including practical!) on Nordic walking. It is fitting, therefore, that this issue includes a systematic review on the evidence for this accessible and increasingly popular whole body physical activity (see page 1577). You will also find two other articles on physical activity promotion and surveillance; Heron et al introduce some early evidence for the positive effects of self-determined pedometer targets over preset ones (see page 1558) and Wanner et al have been researching into a single-item physical activity questionnaire (see page 1570).

\section{ROW, ROW, ROW YOUR BOAT...}

We highlight some medical aspects of rowing in this edition. While the majority of us would not be seeing elite rowers regularly, Dr Fiona Wilson (from the Physiotherapy Department, Trinity College) has brought together a team of authors to emphasise how the lessons learnt from the highest level may be applied to the recreational enthusiast (see page 1525). For example, within Wilson et al's review on predictors of lumbar injury in rowers (see page 1534), they discuss the role of ergometer training, which is particularly relevant to considering the popularity of rowing ergos in gyms. In addition, the 'Myth Busting in Managing Rowing Injuries' paper takes us from cardiac issues to junior rowers, via rib fractures, other injuries and nutritional issues, and highlights how we can all make our management of these conditions more rowing-specific.

AND SOME OF THE REST...

Highlighted as an Editor's choice is a systematic review on return to competitive sport following ACL reconstruction. Clare Ardern et al (see page 1543) have highlighted key predictors of a more positive outcome, such as performance in a symmetrical hopping test and competing at an elite level. Dr Cathy Speed updates the evidence base for shock wave therapy, including its use in tendinopathy (see page 1538). Jonathan Rees revisits the role of inflammation in tendinopathy - the pendulum may be swinging back! This paper (see page 1553) has already had over 25000 page views while Online First-a great place for BJSM subscribers to scan. Lastly, Dr Ruth Verrrelst from Belgium investigates the top down influence of hip musculature in medial tibial pain (see page 1564). As always with these choices, we are emphasising papers that have the potential to be immediately applicable to clinical practice.

\section{SPREAD THE WORD...}

Hopefully something will have perked your interest in this issue, so my challenge to readers this year is to 'pay it forward'. You might consider a journal club, an email update to colleagues, or you could tweet your favourite lesson with a link? Whatever the method, pick a topic and see how far you can distribute the clinical benefits of reading BJSM. And remember, $B J S M$ is much more than the print journal -be sure to check the home page for podcasts (more than 350000 listens), educational videos (over 4 million views) and the archive for the IOC's special issues on Injury Prevention and Health Protection.

Competing interests None.

Provenance and peer review Not commissioned; internally peer reviewed.

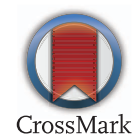

To cite Tillett EJ. Br J Sports Med 2014;48:1521. Accepted 17 September 2014

Br J Sports Med 2014:48:1521. doi:10.1136/bjsports-2014-094218 